\title{
Comparisons of Two Typical Specialized Finite Element Programs for Mechanical Analysis of Cement Concrete Pavement
}

\author{
Hanyan Gu $\mathbb{D}^{1,2,3}$ Xin Jiang $\mathbb{D}^{1,2,3}$ Zhenkun Li, ${ }^{1,2,3}$ Kang Yao, ${ }^{1,2,3}$ and Yanjun Qiu $\mathbb{D}^{1,2,3}$ \\ ${ }^{1}$ School of Civil Engineering, Southwest Jiaotong University, Chengdu 610031, China \\ ${ }^{2}$ Highway Engineering Key Laboratory of Sichuan Province, Southwest Jiaotong University, Chengdu 610031, China \\ ${ }^{3}$ MOE Key Laboratory of High-speed Railway Engineering, Southwest Jiaotong University, Chengdu 610031, China
}

Correspondence should be addressed to Xin Jiang; xjiang01@163.com

Received 9 July 2019; Revised 28 August 2019; Accepted 6 September 2019; Published 25 September 2019

Academic Editor: Alessandro Della Corte

Copyright ( $\odot 2019$ Hanyan Gu et al. This is an open access article distributed under the Creative Commons Attribution License, which permits unrestricted use, distribution, and reproduction in any medium, provided the original work is properly cited.

\begin{abstract}
The structural mechanics analysis of the Portland cement concrete pavement (PCCP) is considerably complicated and distinctive. From the application viewpoint, the capabilities and characteristics of two typical professional finite element software products, named KENSLABS and EverFE, are analyzed. The similarities and differences between these two programs are compared. The comparisons focus on some key factors of modeling and solution strategies, such as element type, meshing, traffic load and temperature curling, boundary conditions, and contact conditions. Based on one specific case example, the two software products were conducted to demonstrate their main functions. The research results clarify the performance of the two software products for structural analysis of cement concrete pavement and indicate each application conditions from their respective features, which can provide valuable references for software users and program developers.
\end{abstract}

\section{Introduction}

As an important part in the transportation infrastructure, Portland cement concrete pavement (PCCP) is generally regarded as a layered system composed of surface course, base course, subbase course, and bed course built on subgrade [1]. Some of the major features of PCCP are summarized below: (1) It consists of several different materials, such as fines, coarse aggregate, cement-stabilized material, and cement concrete, which are of strong nonlinearity, nonuniformity, and anisotropy [2]. (2) The pavement system is repeatedly subjected to various wheel/axle load combinations with different speeds. These loads may be vertical or horizontal. In addition to static effects, the load dynamic effects such as movement, impact, or vibration are very strong $[3,4]$. Furthermore, the positions of the loads are not fixed during the travel time. (3) As been exposed to natural circumstances, Portland cement concrete slabs experience seasonal and daily temperature changes deeply, while the performance of subgrade is also severely dependent on water and temperature conditions [5-8]. (4) The plate should be discontinuous due to longitudinal and transverse joints distributed between adjacent slabs. Transverse joints are often doweled for better load transfer, and adjacent slabs may be tied at longitudinal joints. (5) Many distresses, including blowup, corner break, pumping and water bleeding, transverse and longitudinal cracks, and joint faulting, may occur frequently under the comprehensive influence of traffic loads and temperature changes, thus resulting in the sharp decrease of pavement performance [1].

Carrying out the analysis of the PCCP structure can comprehensively obtain the mechanical response and failure mechanism under the traffic load, temperature gradient, and other environmental factors. It is of great significance for reasonable measures determination, design, and construction technology improvement. Traditional available analytical solutions may not realistically account for complex loads, mixed boundary conditions, and arbitrary geometry [9]. With the development of electronic computers, many different numerical methods have been employed in the rigid pavement structure analysis in the past several decades, such as finite element method (FEM), discrete element 
method (DEM), boundary element method (BEM), and finite difference method (FDM). However, the finite element method is undoubtedly one of the mainstream methods due to its outstanding flexibility and acceptability. As early as 1965, Cheung and Zienkiewicz developed finite element methods for analyzing slabs on elastic foundations of both liquid and solid types [10]. The finite element method (FEM) is useful for both rigid pavement researchers and designers who must perform complex mechanics-based analyses of rigid pavement systems. Many special-purpose programs based on FEM were developed to conduct cement concrete pavement structure mechanical analysis with enough accuracy and higher efficiency. Though general-purpose finite element packages, such as ABAQUS and ANSYS, have powerful ability to handle with complex problems [11-14], they can be difficult to learn and use effectively, model generation can be time-consuming, simulation times can be long in the case of $3 \mathrm{D}$ analysis, and extracting results of interest can be difficult. Therefore, the particularity and complexity of the analysis of the PCCP structure are difficult to be illustrated in details. In the meantime, some specialpurpose software packages were developed for PCCP structural analysis because they address the shortcomings of both the previously described approaches. There are many excellent software products currently available for cement concrete pavement structure analysis, including KENSLABS [15], WESLIQID and WESLAYER [16], ILLI-SLAB [17, 18] (called ISLAB2000 from 2000 [19]), JSLAB [20, 21], RISC [22, 23], DIPLOMAT [24], FEACONS-IV [25], KOLA [26], and EverFE [27]. Most of them are on the basis of the twodimensional finite element method due to the limitation of hardware requirements and computing time. KENSLABS, a 2D program developed by Professor Yang $\mathrm{H}$. Huang of University of Kentucky, and EverFE, a 3D program developed by Professor Bill Davids of University of Maine, are quite distinctive among them. They play a representative role to some degree in the history of PCCP mechanical analysis and have been utilized widely and successfully in the concrete pavement industry [5, 28-31].

The finite element analysis (FEA) studies of the pavement structure currently available emphasize the basic theoretical aspects of the method with applications being presented to demonstrate the essential practical nature of the technique. However, as anyone who has ever tried to develop a finite element program will testify, there is an enormous gulf between the basic theory and a working computer code. In this paper, two typical finite element software packages for PCCP analysis-KENSLABS and EverFE-will be introduced to conduct comparisons from application viewpoints; that is, numerical model establishment, calculation solution strategy, and results postprocessing will be investigated in details. Then, one specific case example is going to be solved by both two programs, respectively, and the resulting differences between them will be discussed. For one thing, this study will help software users to improve these two programs application level. For another, the program developers will get valuable references from these comparisons to release more powerful specialized software. Finally, this study may improve numerical simulation implementation of the PCCP structure by large general-purpose finite element software packages with theory development [32-35].

\section{Comparison of EverFE and KENSLABS}

Similar to other finite element programs, both KENSLABS and EverFE contain three core components to conduct PCCP numerical analysis: numerical model establishment (preprocessing), calculation and solution, results output, and visualization (postprocessing). The details will be circumstantiated below. It should be pointed out that the DOS version of KENSLABS and the Windows version of EverFE 2.24 are discussed for parallel comparisons in this study while there are several versions available currently.

Macroscopically, both programs can be applied to a maximum of 9 slabs and 12 joints. However, surface course can be considered as one-layer or two-layer slabs in KENSLABS. There are three different types of foundations that can be assumed: dense liquid foundation (Winkler foundation), solid foundation, and layer foundation. When a dense liquid foundation is introduced, even the nonuniformity of the foundation can be taken into account. However, if a base or a subbase course is taken into consideration, a layer foundation is recommended for more realistic results. Symmetry of the model can be fully utilized in KENSLABS. As a result, the half-structure or quarter structure can be introduced in analysis to save calculation time and data storage. But the slabs must be rectangular, and this is one minor limitation.

On the contrary, one-layer slab is a default setting in EverFE, and up to 3 elastic base layers can be specified. Each one of them is assumed to be perfectly bonded to the adjacent layer, and the uppermost layer can be completely unbonded with the slab. A tensionless or tension-supporting dense liquid foundation underlies the bottom-most layer. The effects of linear or nonlinear aggregate interlock shear transfer can be simulated at the joints. Two types of elements are utilized to discretize the dowel and tie bars, and the looseness and misalignment of the dowel bars can be modeled perfectly. Every dowel can be precisely located across the transverse joints in the numerical model. Contrary to KENSLABS, the full model must be adopted in EverFE. The slabs can be rectangular or quadrilateral, and this is more flexible than KENSLABS.

2.1. Element Type and Mesh. Thanks to the plate theory, KENSLABS was designed as a two-dimensional (2D) FEM program. The slabs only need to be meshed on the plane. Nonetheless, it needs to be meshed by inputting the grid lines locations of each slab manually. When dividing the slabs into rectangular finite elements, it is not necessary to use very fine divisions. However, the regions near the load or around the area of interest must be meshed finer. In addition, due to the limitations of KENSLABS itself, the total number of nodes is limited to 420 . Up to 15 nodes in the $x$ direction and 15 nodes in the $y$ direction can be set in each slab. To obtain more accurate results, the length-to-width 
ratio of any element should not be greater than 5 . The dimension of the overall stiffness matrix is limited to 70,000 . If the overall stiffness matrix dimension exceeds 70,000 , an iterative method is activated automatically to solve the simultaneous equations. There are one plate element, three types (liquid, solid, and layer) of foundation elements, and one dowel bar element in KENSLABS.

The slabs will be divided evenly by EverFE according to the element number of three directions. Similar to KENSLABS, it is also required that the length-to-width ratio of elements needs to be less than 5 . The total number of elements is theoretically unlimited in EverFE, and the solved problem scale only depends on the computer hardware configurations. Five types of elements are embedded in EverFE, as shown in Figure 1: 20-noded quadratic solid element for discretizing the slabs and elastic base layers, 8-noded planar quadratic element to simulate the dense liquid foundation, 16-noded quadratic interface element to implement aggregate interlock and the slab-base interactions, 3-noded embedded flexible element, and 2-noded shear beam element for discretizing dowel and tie bars.

2.2. Traffic Load and Temperature Gradient. Exposed to natural circumstances, the cement concrete pavement is affected by traffic loads, temperature gradient, and moisture gradient. Different specialized software products treat these factors differently. The following are some tips about the differences when using these two programs.

In terms of loads, rectangular uniformly distributed vertical loads, concentrated forces, and moments can be applied to the KENSLABS model. If uniformly distributed vertical loads are involved, the locations for four sides of the rectangular contact area need to be input manually. However, it is necessary to set the contact pressure for each wheel load area; namely, they can be different from each other. The coordinates of each contact area and the contact pressure should be determined according to the default coordinate system and axle weight prior to simulation. Then, the complex axle combinations can be considered in KENSLABS by adjusting the contact pressure and locations of each loading area, respectively. For fatigue cracking of the slabs caused by load reputations, damage analysis can be carried out to predict the cracking index and design life in KENSLABS. In EverFE, some commonly used axle combinations have been embedded, such as single wheel, single-wheel axle, dual-wheel axle, single-wheel tandem, and dual-wheel tandem. For each axle combination, load parameters can be adjusted according to the contact area, dual spacing, tandem spacing, and spacing between the center of the two sets of dual tires if needed. The contact pressure is calculated automatically on the basis of the contact area and the axle weight; namely, the contact pressure of each contact area should be same. Compared to KENSLABS, concentrated forces or moments cannot be modeled in EverFE.

In the aspect of thermal load, the linear temperature distribution along the thickness is the only selection in
KENSLABS to simulate the thermal load. In contrast, temperature distribution can be linear or nonlinear in EverFE. Up to four temperature change points along the thickness can be defined; i.e., the temperature distribution would be linear, bilinear, or trilinear (illustrated in Figure 2). At the same time, the values at the control points are absolute temperatures specified arbitrarily, rather than relative temperature difference. Therefore, the influence of the overall expansion or contraction on the slab with joint shear transfer can be studied. This would be an equivalent method to simulate the early shrinkage effect of PCCP in the meanwhile.

2.3. Boundary Conditions. In KENSLABS, $x$ and $y$ directions' (the horizontal direction) displacements of the nodes are fixed, due to the basic assumptions of the plate theory. The foundation (dense liquid foundation, layer foundation, or solid foundation) provides the $z$ direction constraint. It occurs when the slabs and foundation are in contact, which can be judged by the program itself or defined by users.

EverFE differs its default boundary conditions depending on whether there is an elastic base layer: (1) If the base layer is involved in the model, the shear stiffness of the slab-base interface element constrains the displacement of the slab in the $x$ and $y$ directions, and the $z$ direction constraint is obtained by contact with the base layer. The rigid body motion of the base layer and the subbase layer is prevented by limiting the displacement in the $x$ and $y$ directions of a node on the $x$-face and limiting the $x$-displacement of a second node on the $x$ face. (2) If the slabs are modeled directly on a dense liquid foundation, i.e., no base layer is modeled, each slab is restrained against $x$ and $y$ directions' displacements at one node on its $x$-face and against $x$-direction displacement at a second node on its $x$-face to prevent rigid body motion of each slab. Vertical support is provided by the dense liquid foundation. The $z$ direction support constraints of the overall system are provided by dense liquid foundation. These conditions are always present by default and are not graphically displayed during modeling; namely, no additional manual specification is required.

2.4. Contact Simulation. The contact relationships involved in the PCCP structure have a great influence on the mechanical responses and need to be paid enough attention. These contact relationships include the interaction between slab and base, slab and foundation, one slab and another slab, dowel bar or tie bar, and slab.

About the contact between slab and base, a bound or unbound two-layer slab can be simulated in KENSLABS, while the lower layer can be regarded as the base layer. To capture slab-base shear transfer, EverFE employs 16-noded zero-thickness quadratic interface elements that are meshed between the slab and base, as shown in Figure 3 . The sliding of slab and base layer is defined by two constitutive parameters: initial distributed stiffness and slip 


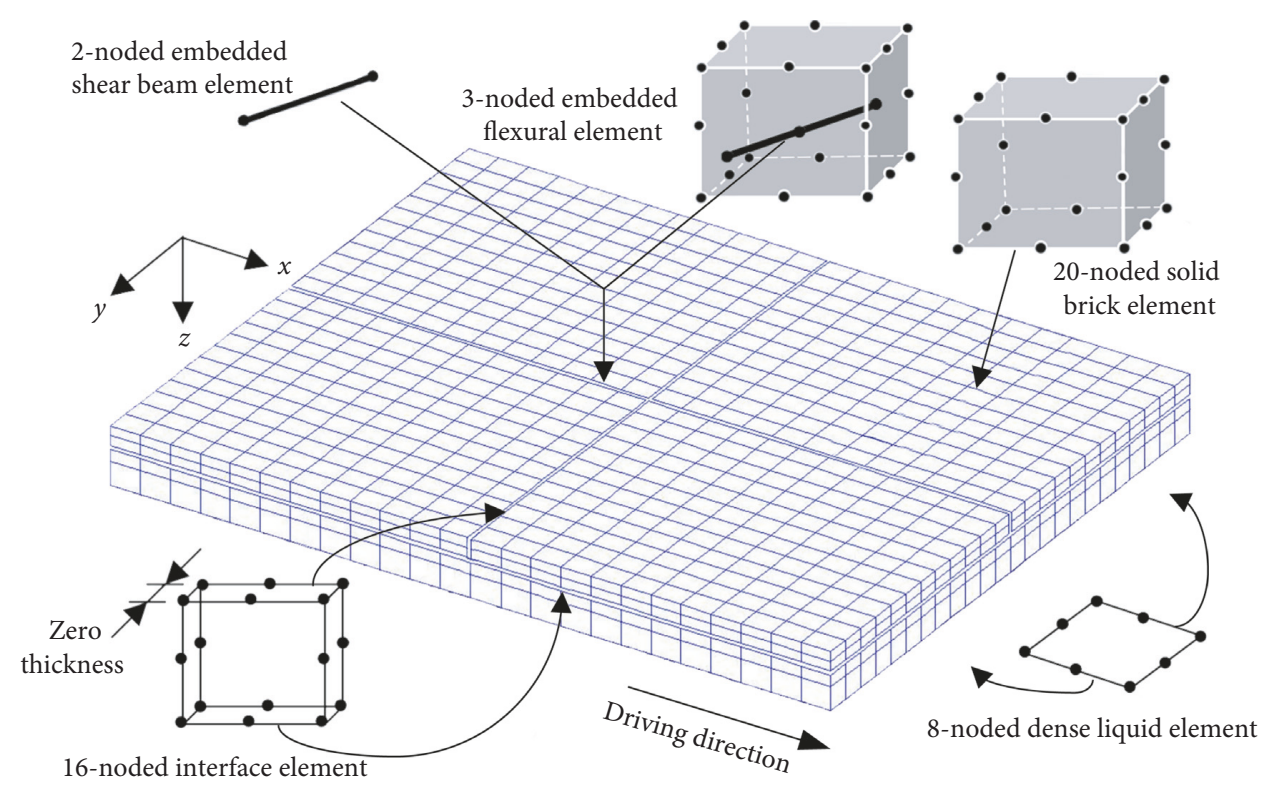

Figure 1: Five types of elements embedded in EverFE [36].

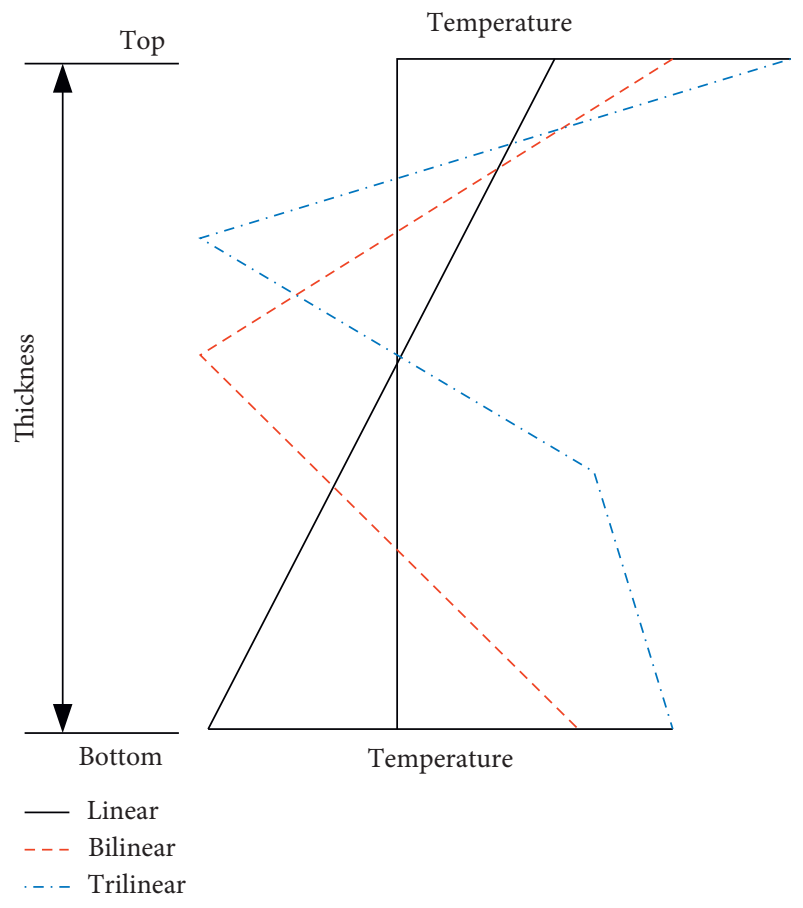

FIgURE 2: Temperature distribution models in EverFE.

displacement, which is similar to an elastic-plastic model. The slab elements and base elements will not share the nodes in any case, thanks to such a process.

The consideration approach of KENSLABS and EverFE is quite distinctive for the contact between slab and foundation, and KENSLABS can assume that some nodes may not always in contact with the foundation; namely, gaps may occur after being loaded. In the meanwhile, the iteration method can be adopted to determine if the slab is in contact with the foundation. It is also possible to specify the initial

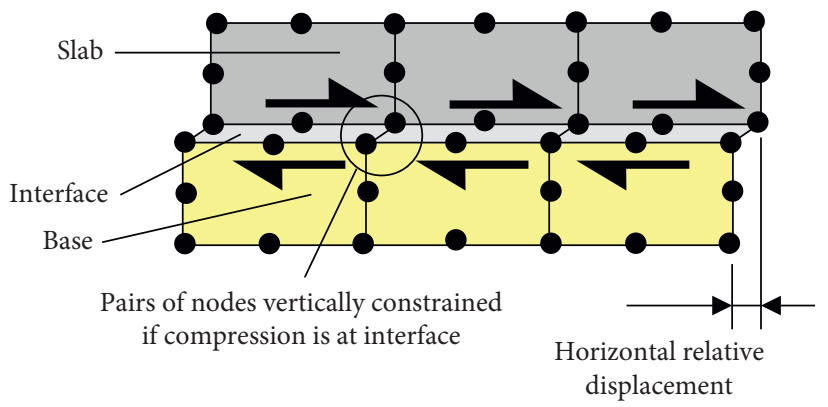

FIgURE 3: Tangential contact between the slab and base in EverFE [36].

gap values at some nodes, and the program will determine whether the slab is in contact with the foundation after being loaded. That is to say, the contact condition of slab and foundation can be defined as full contact, partial contact without initial gap, or partial contact with initial gap (liquid foundation) in KENSLABS. However, only the full contact is assumed in EverFE because it is available for most of the time.

To simulate the interactions between one slab and another slab at the joint, dowel or tie bar, and slab, there are generally four methods as follows in finite element analysis: (1) a spring element connects two adjacent slabs directly; (2) a beam element directly connects two slabs; (3) a beam element connects two concrete slabs by spring elements; (4) three-dimensional (3D) solid elements are utilized to describe the contact behaviors. In KENSLABS, a more concise method is selected, the first one, as shown in Figure 4(a). Whether there are dowels or ties, interactions should be converted into a shear spring constant and a moment spring constant at the adjacent nodes by a certain method. In EverFE, the joint simulation is implemented by the second and third method mentioned above. When the looseness of 


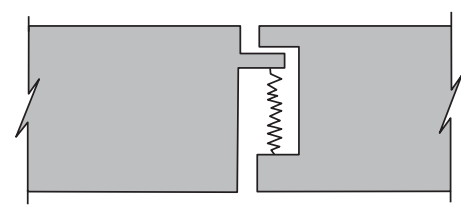

(a)

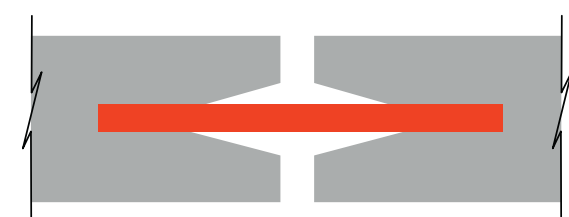

(b)

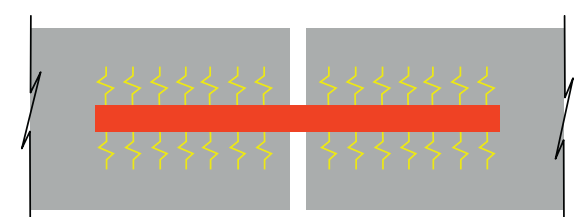

(c)

FIGURE 4: Simulation methods of the joint in the two programs [1, 36]: (a) spring element; (b) beam element; (c) spring and beam element.

dowel is considered, the second one is activated automatically. The embedded flexural elements are directly connected to the concrete slab; both ends are embedded in the concrete, and the gaps are symmetrically distributed on both sides of the joint, as shown in Figure 4(b). It can be seen that the model is nonlinear when the method is adopted. However, if the combined method in Figure 4(c) is activated, that is the third method, the looseness of the dowels cannot be considered. At this time, the model is still linear, which is more convenient for calculation. The computation time is saved, and satisfactory results can also be obtained. More details are shown in Figure 4.

2.5. Solution Strategies. KENSLABS follows the general solution strategies of conventional analysis (stress and displacement): the overall stiffness matrix is obtained by superimposing the stiffness matrix of the foundation, joints, and slabs. The uniform load is converted into the nodal force, and then the nodal force vector is formed. Therefore, the displacement matrix can be obtained by solving simultaneous equations, and then the stress and strain of the node can be solved by the mechanical method. Gauss elimination is employed to solve the problem. Of course, some unusual features can be seen in KENSLABS. Considering when the foundation is liquid foundation, the slab may cause the separation of the slab and foundation with loading, temperature curling, and self-weight. Or the slabs are not in contact with the foundation on the initial condition, and the contact behavior may occur after loading, temperature curling, and self-weight. The program introduces an iterative idea to solve such a situation. Update the assumption of the contact condition in the initial state over and over again until the assumption is consistent with the calculation result. Moreover, the stiffness matrix is iterated too in such processing. This is of great significance for the analysis of the nonlinearity of the contact between the slab and foundation.

The solution strategies of EverFE for general linear and nonlinear analysis resemble to KENSLABS. However, iteration is introduced only in the process of solving simultaneous equations in EverFE. The displacement increment matrix is obtained by the residual force vector in each iteration. Then, the stiffness matrix updates. The displacement increment is superimposed cyclically, and the node displacement matrix is obtained when the residual force vector sufficiently is close to zero. Multigridpreconditioned conjugate gradient (MG-PCG) solver is developed specifically for efficient computation. The stiffness matrix in this iterative process is nonlinear due to the problem (considering shear transfer between the slab and the base layer, using a dense liquid foundation that is tensionless, looseness of the dowels, or selecting a nonlinear aggregate interlock model).

The comparison of the two software packages solution strategies is shown in Figure 5.

2.6. Results Output and Visualization. KENSLABS can output the calculation results directly in text format to computer hard disk, such as temperature curling, $z$-displacement, plane stress, principal stress, shear of dowels, and cracking index. All the input parameters during model establishment are also output in the same TXT file to check the data correctness. The results can only be visualized by some third-party powerful visualization tools like ORIGIN, SURFER, and ParaView.

EverFE couples a highly interactive graphical user interface for result visualization written in Tcl/Tk/Tix/ vTk. Its strong visualization capabilities and prominent postprocessing capabilities can display the stresses, displacements, dowel shear, and moment in the graphical interface. Critical response values at any point in the model can be easily retrieved. More importantly, the views can be curves, cloud map, or contour map on any $x$, $y$, or $z$ planes. Additionally, similar to KENSLABS, all the model parameters and calculation results are saved to computer hard disk in text format.

\section{Example and Discussion}

3.1. Problem Description. Since only the liquid foundation can be applied in EverFE, appropriate modification of the example in the literature [1] is made. Then, a particular example is designed to illustrate the respective characteristics of two programs. Assume that there is a two-slab system on a liquid foundation subjected to a dual-wheel tandem axle load with a total weight of $142.4 \mathrm{kN}$. The front axle is applied at the joint with the outside loaded area adjacent to the pavement edge. Assume that the slab is in full contact with the foundation.

3.2. Finite Element Model. According to the model parameters shown in Table 1, the finite element models established by two software packages are diagramed in Figure 6. As mentioned above, since the limitation of present dimensions of KENSLABS, the finer meshes are 


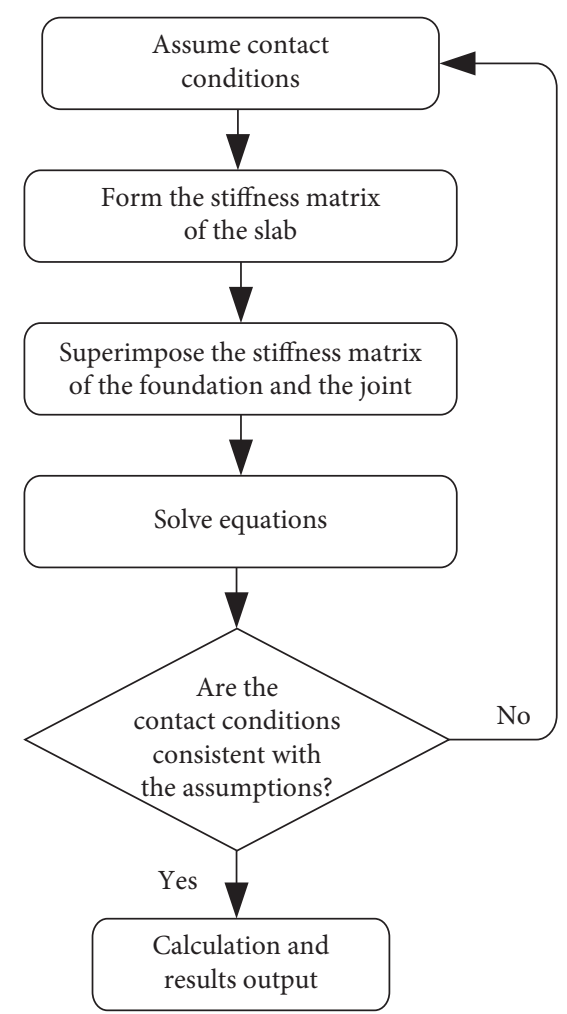

(a)

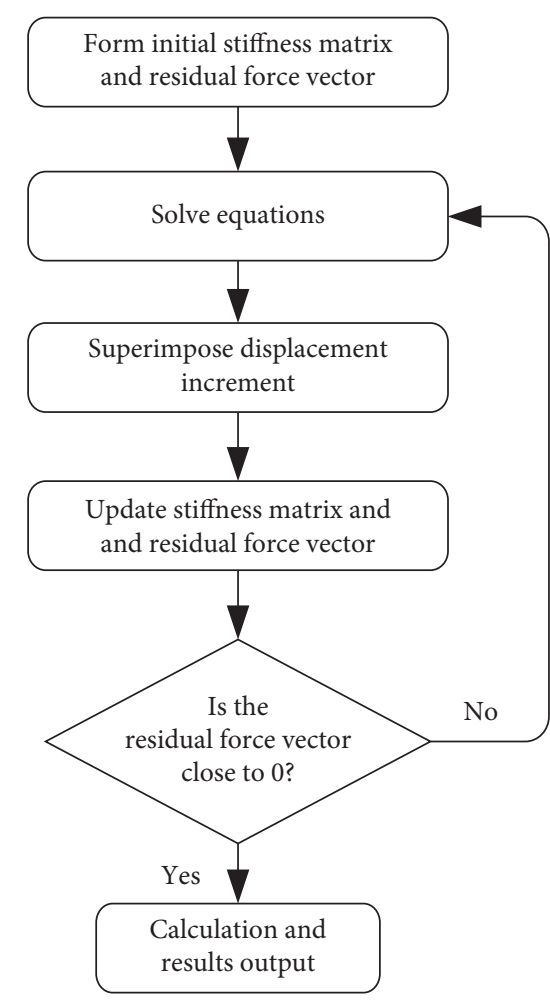

(b)

FIgURE 5: Solution strategies comparisons of the two programs: (a) KENSLABS; (b) EverFE.

TABLE 1: Parameters of finite element models.

\begin{tabular}{|c|c|c|}
\hline Parameter type & KENSLABS & EverFE \\
\hline Axle load & \multicolumn{2}{|c|}{$\begin{array}{l}\text { (i) Eight } 204.1 \mathrm{~mm} \times 140.5 \mathrm{~mm} \text { rectangular uniform loads } \\
\text { (ii) Contact pressure: } 620.6 \mathrm{kPa} \\
\text { ing: } 336.1 \mathrm{~mm} \text {, tandem spacing: } 1208.8 \mathrm{~mm} \text {, and the overall width: } 2317.7 \mathrm{~mm} \text {. }\end{array}$} \\
\hline Slab & \multicolumn{2}{|c|}{$\begin{array}{l}\text { (i) } 4572 \mathrm{~mm} \text { (length) } \times 3657.6 \mathrm{~mm} \text { (width) } \times 178 \mathrm{~mm} \text { (thickness) } \\
\text { (ii) Joint width: } 5.0 \mathrm{~mm} \\
\text { (iii) Elastic modulus: } E_{1}=27580 \mathrm{MPa} \text {, Poisson's ratio: } \nu_{1}=0.15 \text {, and unit weight: } \gamma=23.58 \mathrm{kN} / \mathrm{m}^{3} \text {. }\end{array}$} \\
\hline Dowel & \multicolumn{2}{|c|}{ 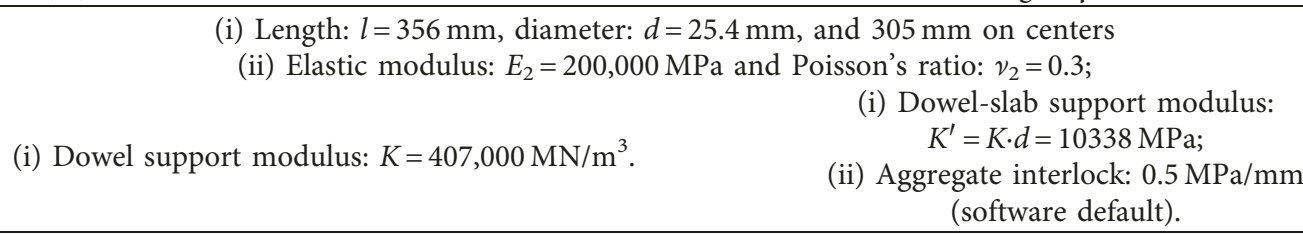 } \\
\hline Liquid foundation & (i) Reaction modulus: $54.2 \mathrm{MN} / \mathrm{m}^{3}$. & (i) Reaction modulus: $0.0542 \mathrm{MPa} / \mathrm{mm}$ \\
\hline
\end{tabular}

only applied to the wheel paths (diagramed in Figure 6(a)), which is helpful to improve the calculation accuracy. The mesh in Figure 6(a) is identical to the literature [1]. Contrary to KENSLABS, such a restriction is overcome in EverFE, so the mesh can be properly refined. Meanwhile, the length-to-width ratio of the element is strictly limited. The coordinate system employed by the two programs is quite different. KENSLABS, the results are saved in text format, which needs to be processed by other visualization programs. The results of EverFE calculation can be directly displayed in graphics and saved in text format. Some other visualization tools are utilized to visualize the results for parallel comparisons. Since there are the discrepancies of coordinate systems between the two software products, a self-defined coordinate system is employed for more intuitive comparison. In this section, the coordinate origin and the $x$ and $y$ direction are corresponding to Figure 6(b), and upward is positive for the $z$ axis. The compression stress is considered as positive.

The displacement in $z$ direction, the stress at the bottom of the slab, and the shear in $z$ direction at the joint (the 


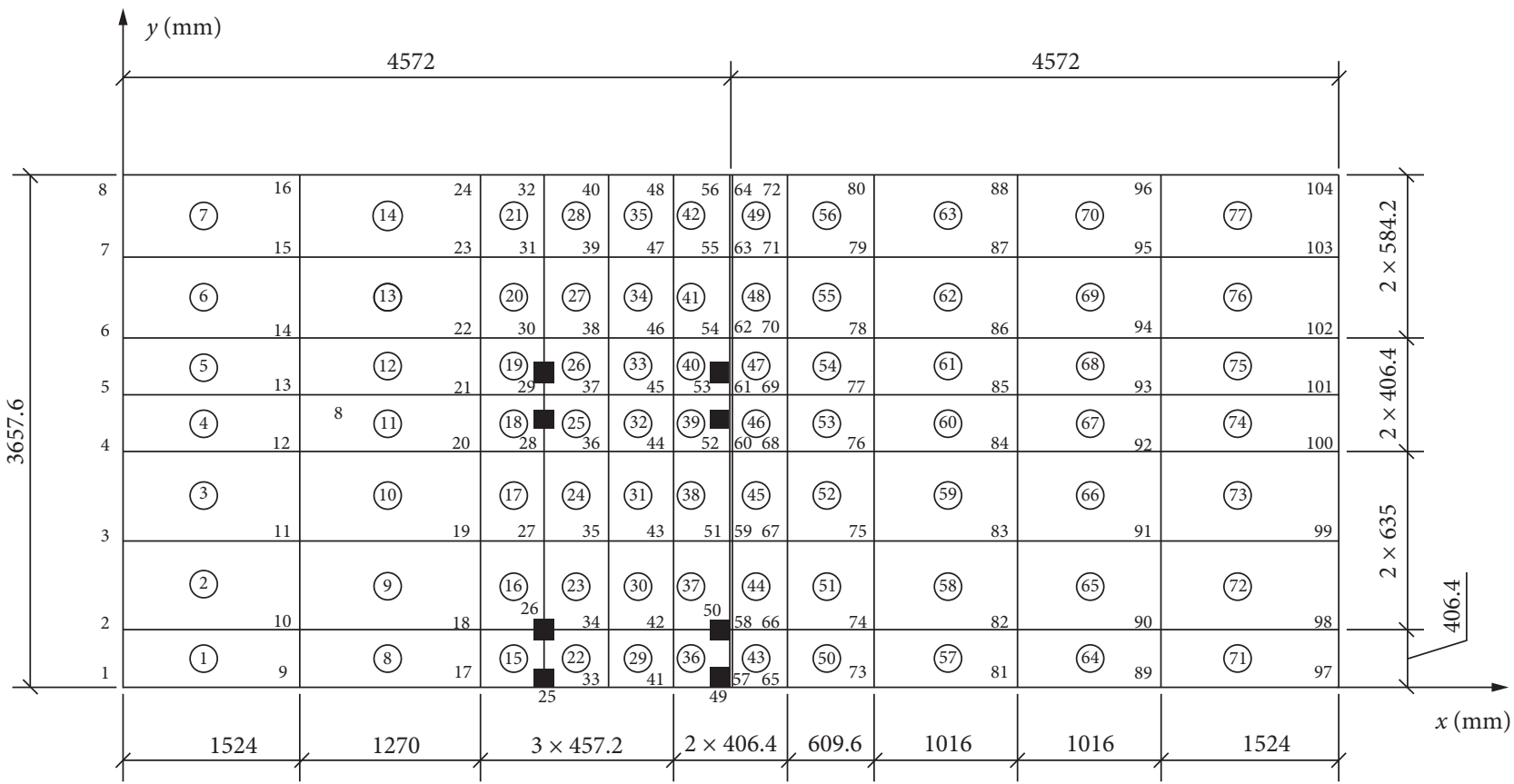

(a)

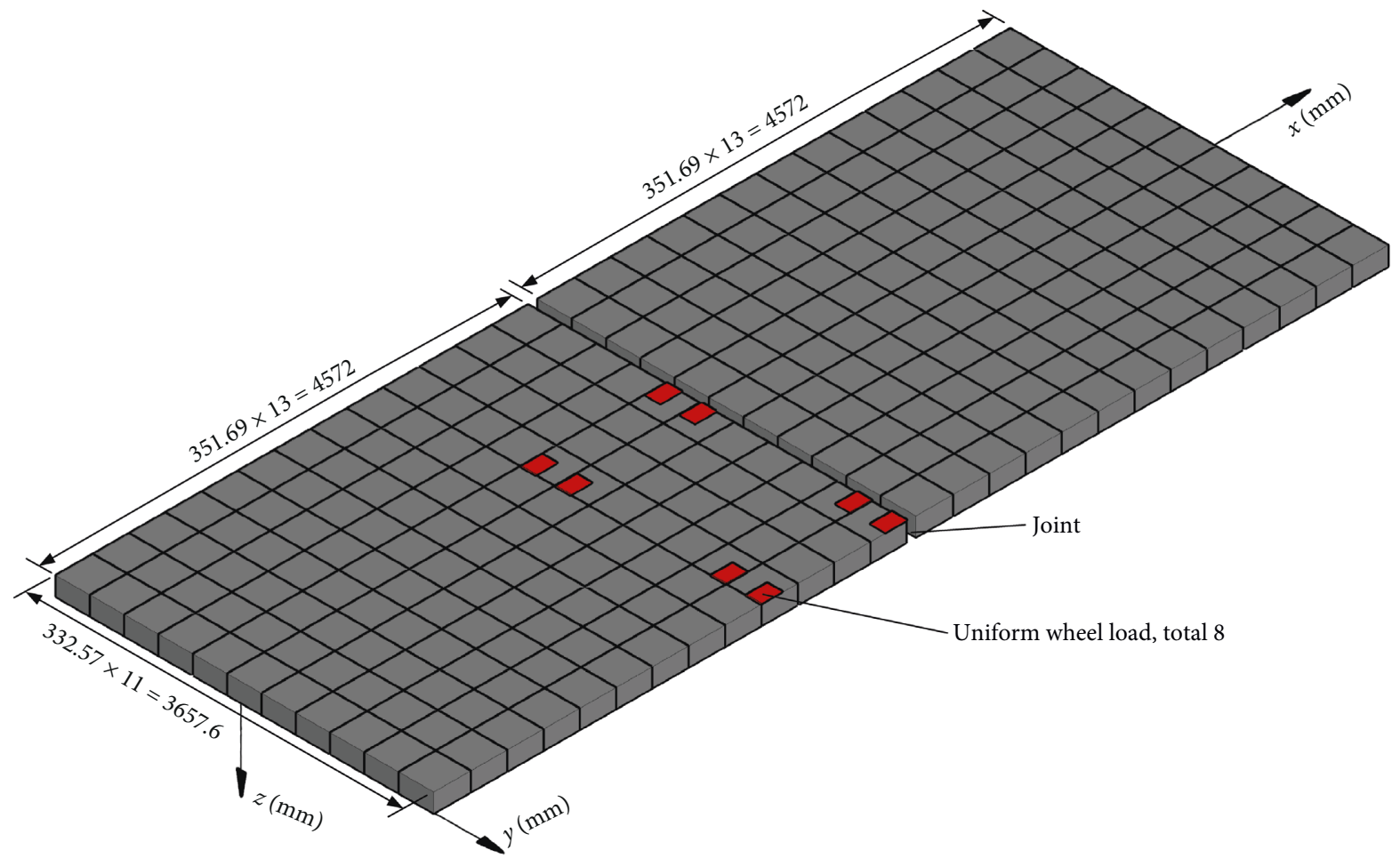

(b)

FIgURE 6: Finite element models of the two programs: (a) KENSLABS; (b) EverFE.

dowels) calculated by KENSLABS, and the $z$ direction displacement of the top of the slab, the stress at the bottom of the slab, the $z$ direction shear and the moment of the dowels along the length, and the $z$ direction shear of the dowels at the joint calculated by EverFE are plotted in Figures 7-10, respectively.
The calculation results of the case example above illustrate the following: (1) the macroscopic deformations of the slab obtained by the two software packages are similar; the maximum displacement values are $-0.80 \mathrm{~mm}$ and $-0.89 \mathrm{~mm}$, respectively; and the load transfer efficiency (LTE) of the dowel bar expressed by the deflection ratio is 


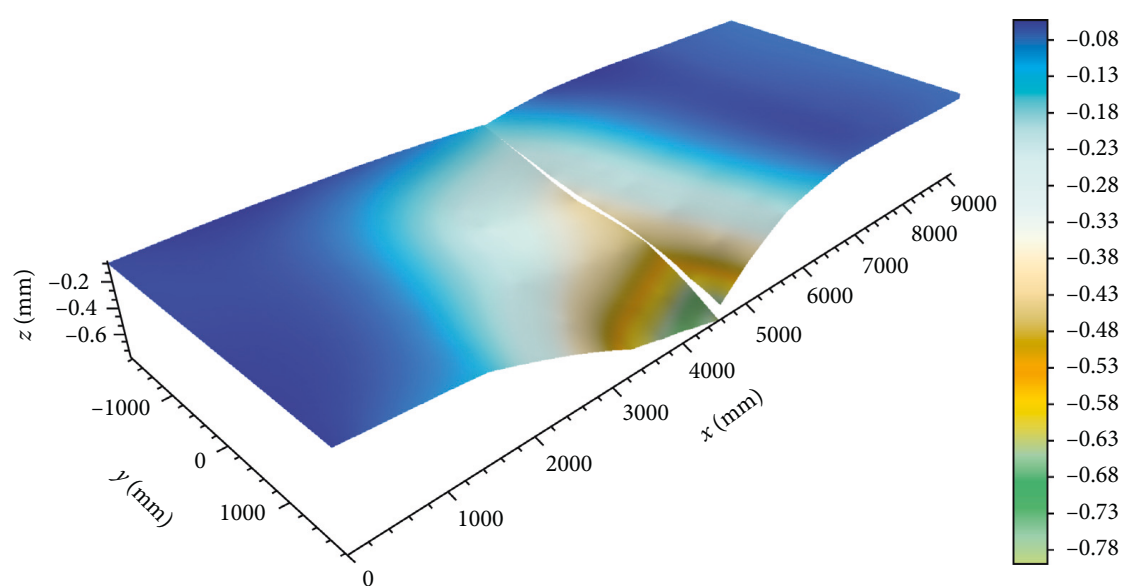

(a)

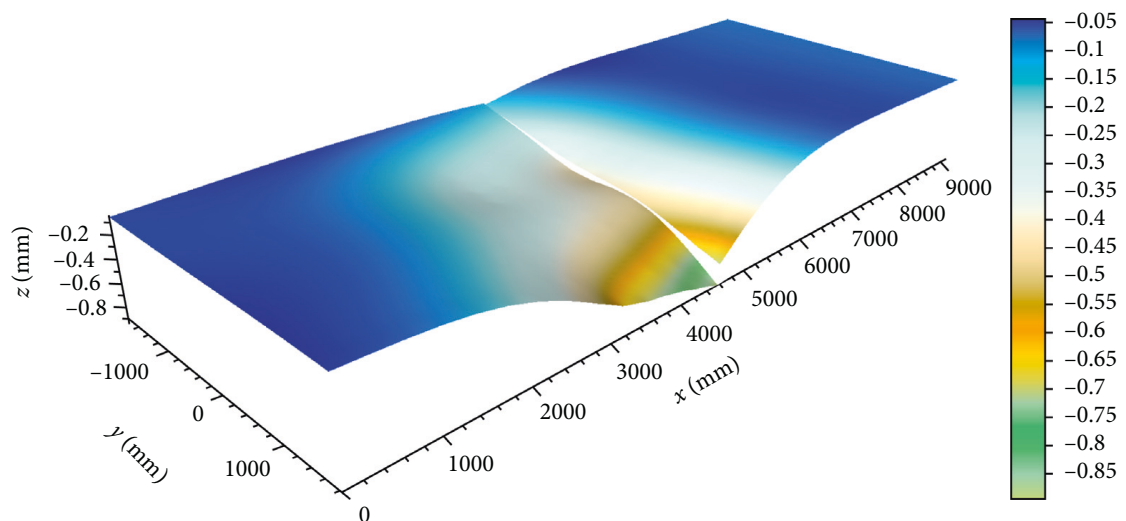

(b)

FIGURE 7: Spatial deflection distribution of the two programs: (a) $z$ direction displacement of KENSLABS; (b) $z$ direction displacement of slab top of EverFE.

$80 \%$ and $83 \%$, respectively. The results are in good agreement. (2) The two software packages are corresponding in stress results mostly, but partial discrepancies occur close to the (transverse) joint, owing to the different simulation method of the dowels and ties. (3) The macroscopic distributions of the dowel shear calculated by the two software packages are relatively congruous; however the different simulation methods should account for the discrepancies. (4) In terms of the output of the mechanical responses of the dowels, the distribution of the shear and moment along the length can be received directly in EverFE.

\section{Conclusions and Suggestions}

The development ideas, analytical capabilities, and solution strategies of two typical PCCP structure analysis software products-KENSLABS and EverFE-are comprised, and their functions are demonstrated in combination with a case example.

(1) The structural analysis of PCCP is complex and distinctive under traffic load and temperature change. Both programs can be applied to simulate reality after necessary simplifications and idealizations. The specific case example shows that the macroscopic deformation law and the critical responses at some key locations obtained from two programs are in good agreement.

(2) Based on 3D FEM theory, EverFE can get the mechanical responses of concrete pavement with more structural layers and elements by powerful computer hardware. The distribution of the shear force and the moment of dowels along the length can also be obtained. Special conditions such as trapezoidal slab and nonlinear temperature distribution can also be modeled. Moreover, the user-friendly preprocessing graphical interface and visualization capabilities are the advantages compared to KENSLABS. EverFE is an excellent FEM software package which is suitable for conventional mechanical analysis. It comes with outstanding performance in joint nonlinearity and nonlinear temperature gradient simulation.

(3) KENSLABS developed on plate elements can consider many important factors of PCCP structural analysis, including nonliquid foundations, initial gaps between slab and foundation, and foundation nonuniformity with limited computational resources. Fatigue cracking damage 


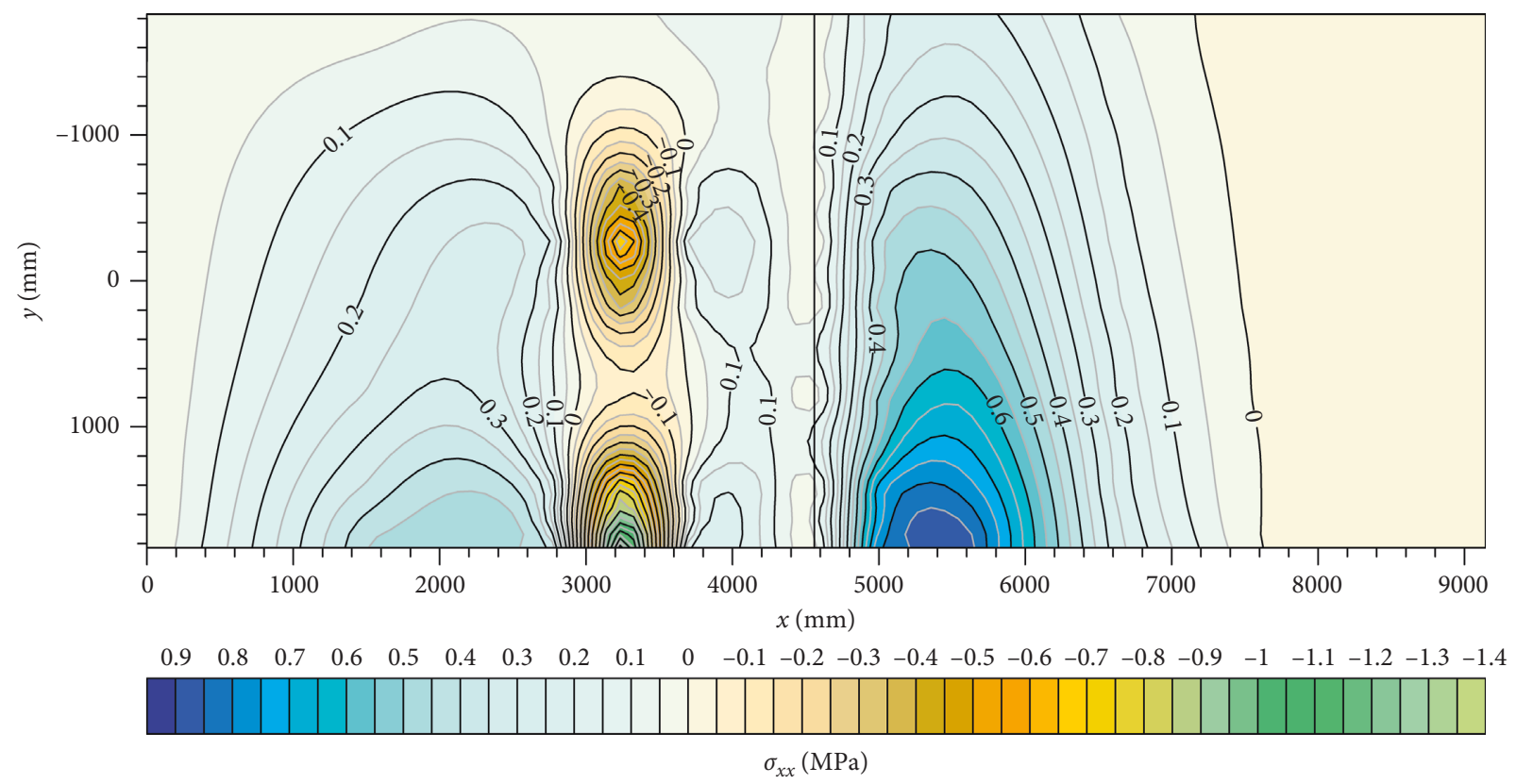

(a)

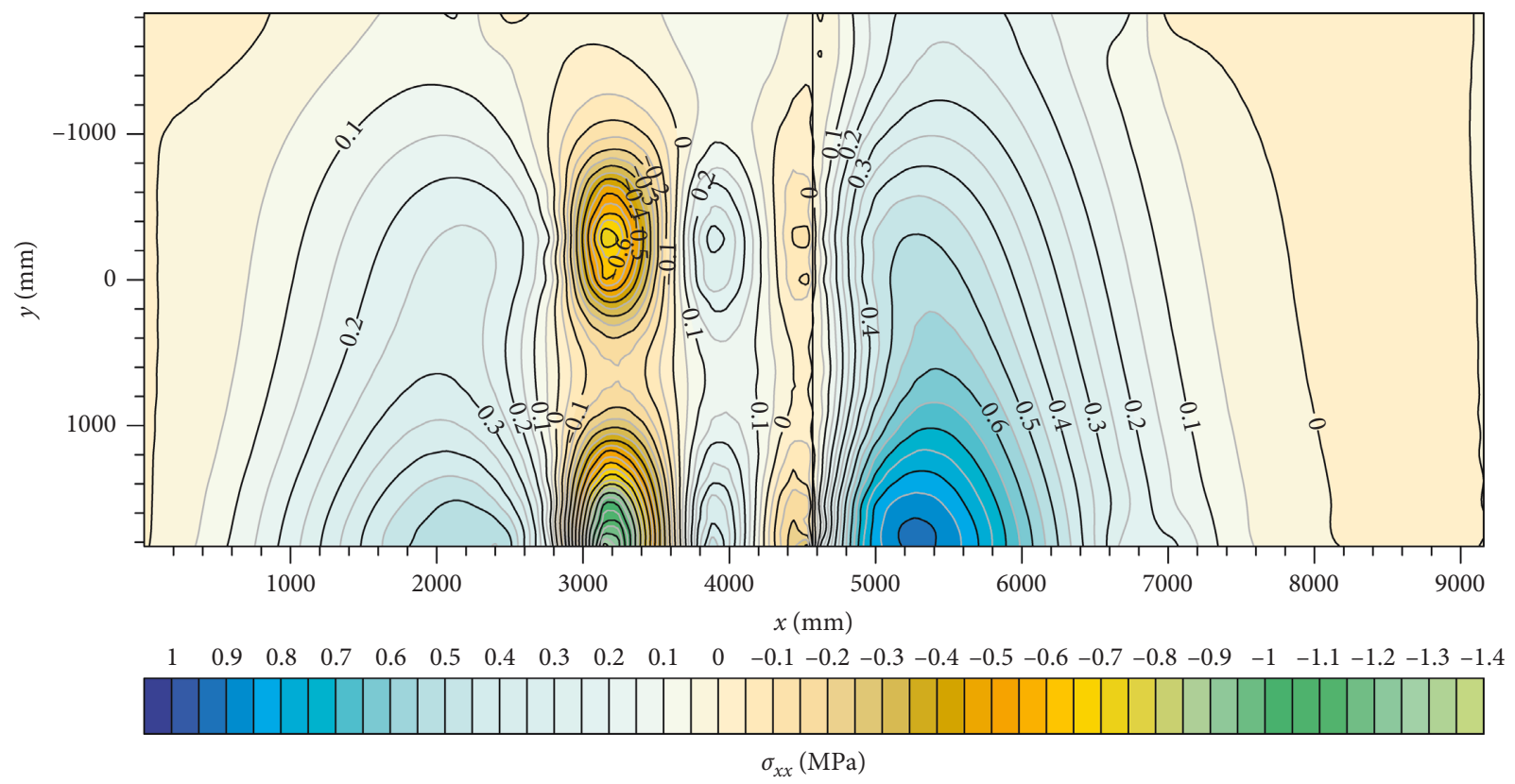

(b)

FIGURE 8: Stress distribution at the bottom of the driving direction of the two programs: (a) KENSLABS; (b) EverFE.

analysis can be performed by dividing each year into a maximum of 24 periods, each with a maximum of 24 load groups. As a highly simplified 2D FEM program, KENSLABS is restricted by the personal computer performance when developing. However, it has outstanding advantages in the unconventional analysis of PCCP, such as initial gaps and damage analysis. The calculation accuracy has been proved after application over thirty years. Now this version has been constantly updated and improved to Windows version (KENPAVE). If the functions of KENSLABS retain or extend and user interface is enhanced, a better special-purpose finite element program for cement 


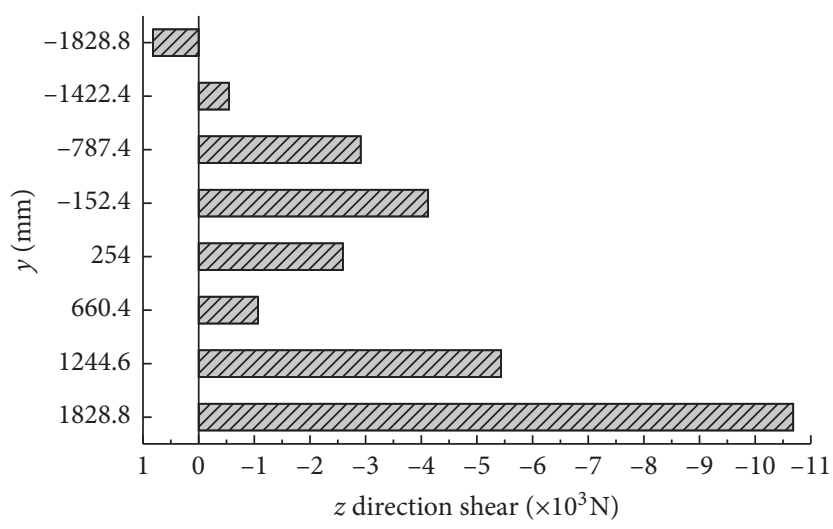

(a)

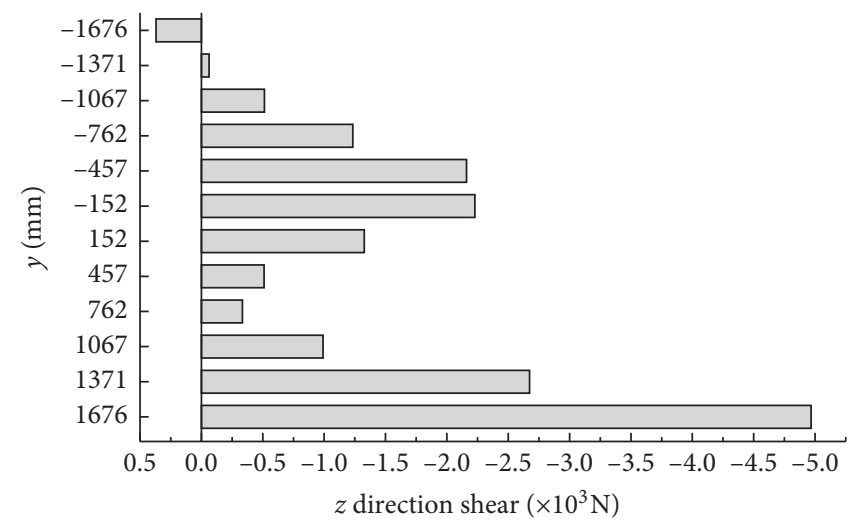

(b)

FIgURE 9: $z$ direction shear force of the dowel bars at the joint of the two programs: (a) KENSLABS; (b) EverFE.

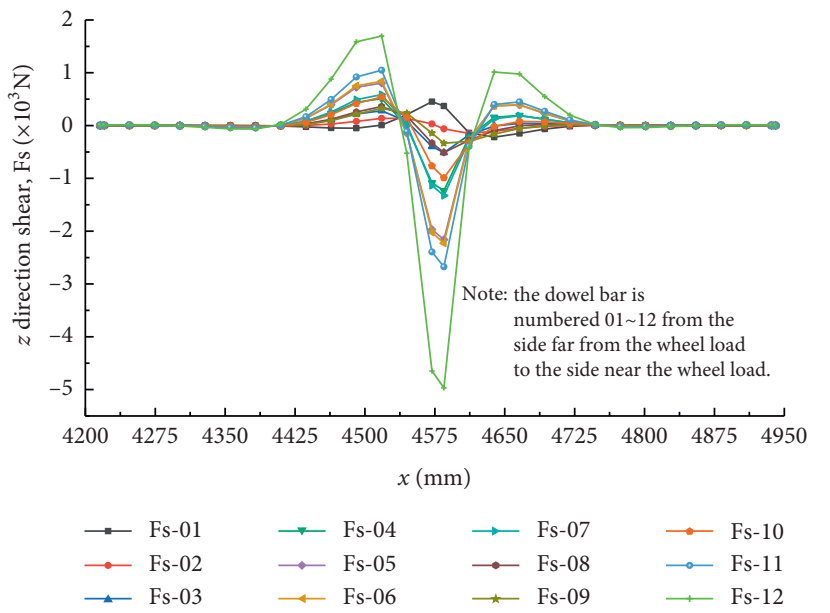

(a)

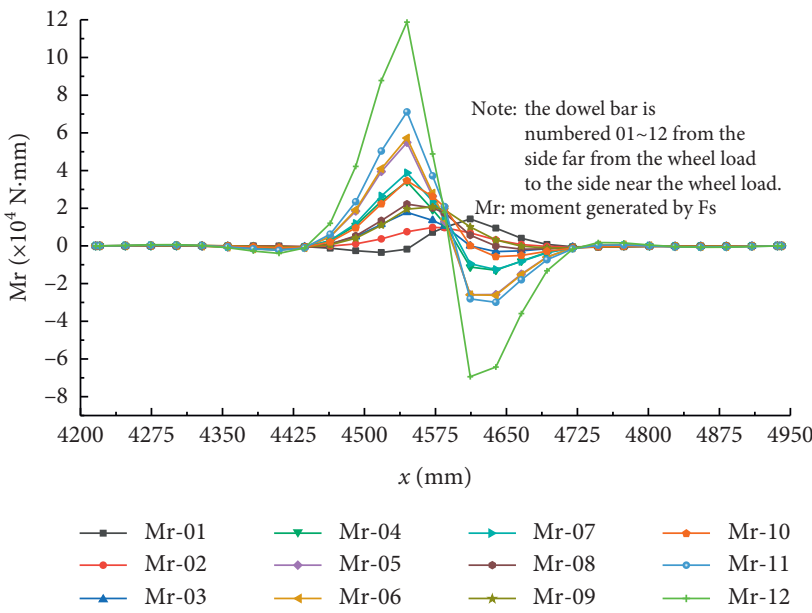

(b)

FIgURE 10: The distributions of the shear force and moment of the dowels along the length of the bars obtained by EverFE: (a) $z$ direction shear force distribution along the length of the dowels; (b) distribution of moment along the length of the dowels.

concrete pavement analysis shall be developed by that time.

\section{Data Availability}

The data used to support the findings of this study are included within the article. All the data were obtained by EverFE and KENSLABS based on the parameters in this article.

\section{Conflicts of Interest}

The authors declare that they have no conflicts of interest.

\section{Acknowledgments}

The research was supported by Sichuan Science and Technology Program (Grant no. 2019YFS0492) and National Natural Science Foundation of China (Grant no. 51378440).

\section{References}

[1] Y. H. Huang, Pavement Analysis and Design, Prentice Hall, Upper Saddle River, NJ, USA, 2004.

[2] Y. Liu, Z. You, L. Li, and W. Wang, "Review on advances in modeling and simulation of stone-based paving materials," Construction and Building Materials, vol. 43, pp. 408-417, 2013.

[3] A. E. A. El-Maaty, G. M. Hekal, and E. M. S. El-Din, "Modeling of dowel jointed rigid airfield pavement under thermal gradients and dynamic loads," Civil Engineering Journal, vol. 2, no. 2, pp. 38-51, 2016.

[4] H. Ouyang, "Moving-load dynamic problems: a tutorial (with a brief overview)," Mechanical Systems and Signal Processing, vol. 25, pp. 2039-2060, 2011.

[5] Y. Wu, X. Jiang, and D. Wang, "Subgrade-associated factorial influences on fatigu," International Journal of Science and Engineering Investigations, vol. 6, no. 62, pp. 97-104, 2017.

[6] P. Mackiewicz, "Thermal stress analysis of jointed plane in concrete pavements," Applied Thermal Engineering, vol. 73, no. 1, pp. 1169-1176, 2014. 
[7] Y. Qin and J. E. Hiller, "Modeling temperature distribution in rigid pavement slabs: impact of air temperature," Construction and Building Materials, vol. 25, no. 9, pp. 3753-3761, 2011.

[8] Y. Wei, S. Liang, and X. Gao, "Numerical evaluation of moisture warping and stress in concrete pavement slabs with different water-to-cement ratio and thickness," Journal of Engineering Mechanics, vol. 143, no. 2, 2017.

[9] H. M. Westergaard, "Stresses in concrete pavements computed by theoretical analysis," Public Roads, vol. 7, no. 1926, pp. 25-35, 1926.

[10] Y. K. Cheung and O. C. Zinkiewicz, "Plates and tanks on elastic foundations - an application of finite element method," International Journal of Solids and Structures, vol. 1, no. 4, pp. 451-461, 1965.

[11] V. Sadeghi and S. Hesam, "Investigation of load transfer efficiency in jointed plain concrete pavements (JPCP) using FEM," International Journal of Pavement Research and Technology, vol. 11, no. 3, pp. 245-252, 2018.

[12] T. W. Aure and A. M. Ioannides, "Fracture analysis of aggregate interlock jointed slabs-on-grade," Construction and Building Materials, vol. 77, pp. 340-348, 2015.

[13] M. Y. Darestani, D. P. Thambiratnam, A. Nataatmadja, and D. Baweja, "Structural response of concrete pavements under moving truck loads," Journal of Transportation Engineering, vol. 133, no. 12, pp. 670-676, 2007.

[14] Y. Dere, A. Asgari, E. D. Sotelino, and G. C. Archer, "Failure prediction of skewed jointed plain concrete pavements using 3D FE analysis," Engineering Failure Analysis, vol. 13, no. 6, pp. 898-913, 2006.

[15] Y. H. Huang and S. T. Wang, "Finite-element analysis of concrete slabs and its implications for rigid pavement design," in Proceedings of the 52nd Annual Meeting of the Highway Research Board, pp. 55-69, Washington, DC, USA, January 1973.

[16] Y. Chou, "Structural analysis computer programs for rigid multicomponent pavement structures with discontinuities-WESLIQID and WESLAYER," Technical Report GL-81-6, Geotechnical Laboratory, U.S. Army Engineer Waterways Experiment Station, Vicksburg, MS, USA, 1981.

[17] A. M. Tabatabaie and E. J. Barenberg, "Longitudinal joint systems in slip-formed rigid pavements," Report FAA-RD-794, III, vol. 3, U. S. Department of Transportation, Washington, DC, USA, 1979.

[18] A. M. Tabatabaie and E. J. Barenberg, "Structural analysis of concrete pavement systems," Transportation Engineering Journal, ASCE, vol. 106, no. TE5, pp. 493-506, 1980.

[19] L. Khazanovich, H. T. Yu, S. Rao et al., ISLAB2000-Finite Element Analysis Program for Rigid and Composite Pavements: User's Guide, ARA, Inc., ERES Consultants Division, Champaign, IL, USA, 2000.

[20] S. D. Tayabji and B. E. Colley, "Improved pavement joints," in Transportation Research Record 930, TRB, pp. 69-78, National Research Council, Washington, DC, USA, 1983.

[21] S. D. Tayabji and B. E. Colley, "Analysis of jointed concrete pavement," Report No. FHWA-RD-86-041, Federal Highway Administration, Washington, DC, USA, 1986.

[22] K. Majidzadeh, G. J. Ilves, and H. Sklyut, "Mechanistic design of rigid pavements, development of the design procedure," Report No. FHWA-RD-86-124, vol. 1, Federal Highway Administration, Washington, DC, USA, 1984.

[23] K. Majidzadeh, G. J. Ilves, and H. Sklyut, "Mechanistic design of rigid pavements, design and implementation manual," Report No. FHWA-RD-86-235, vol. 2, Federal Highway Administration, Washington, DC, USA, 1984.
[24] L. Khazanovich and A. M. Ioannides, "DIPLOMAT: analysis program for bituminous and concrete pavements," in Transportation Research Record 1482, TRB, pp. 52-60, National Research Council, Washington, DC, USA, 1995.

[25] M. Tia, D. Bloomquist, B. E. Ruth et al., "Field evaluation of rigid pavement design system-phase III," Final Report, University of Florida, Gainesville, FL, USA, 1988.

[26] A. W. M. Kok, "A PC program for the analysis of rectangular pavements structures," in Proceedings of the 2nd International Workshop on the Design and Rehabilitation of Concrete Pavements, pp. 113-120, Sigüenza, Spain, October 1990.

[27] W. G. Davids, G. M. Turkiyyah, and J. P. Mahoney, "EverFE: rigid pavement three-dimensional finite element analysis tool," Transportation Research Record: Journal of the Transportation Research Board, vol. 1629, no. 1, pp. 41-49, 1998.

[28] Y. Zhang and L. Gao, "Effect of dowel bar position deviation on joint load-transfer ability of cement concrete pavement," International Journal of Pavement Research and Technology, vol. 9, no. 1, pp. 30-36, 2016.

[29] L. Moretti, P. Di Mascio, and F. Panunzi, "Economic sustainability of concrete pavements," Procedia-Social and Behavioral Sciences, vol. 53, pp. 125-133, 2012.

[30] Z. Zhang and S. Tighe, "Impact of tridem and trunnion axle groups on premature damage of pavement infrastructure," Canadian Journal of Civil Engineering, vol. 34, no. 2, pp. 156-161, 2007.

[31] E. A. Jensen and W. Hansen, "Nonlinear aggregate interlock model for concrete pavements," International Journal of Pavement Engineering, vol. 7, no. 4, pp. 261-267, 2006.

[32] A. Cazzani, N. L. Rizzi, F. Stochino et al., "Modal analysis of laminates by a mixed assumed-strain finite element model," Mathematics and Mechanics of Solids, vol. 23, no. 1, pp. 99119, 2016.

[33] A. Cazzani, M. Serra, F. Stochino et al., "A refined assumed strain finite element model for statics and dynamics of laminated plates," Continuum Mechanics and Thermodynamics, 2018.

[34] I. H. H. Al-Ghafri and M. A. Javid, "Comparative analysis of rigid pavement using westergaard method and computer program," Journal of Soft Computing in Civil Engineering, vol. 2, no. 2, pp. 19-30, 2018.

[35] J. H. Jeong, J. Y. Park, J. S. Lim et al., “Testing and modelling of friction characteristics between concrete slab and subbase layers," Road Materials and Pavement Design, vol. 15, no. 1, pp. 114-130, 2014.

[36] B. Davids, EverFE Theory Manual, University of Maine, ME, USA, 2003. 


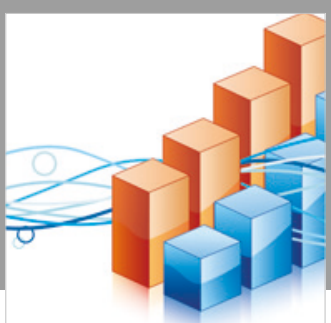

Advances in

Operations Research

\section{-n-m}
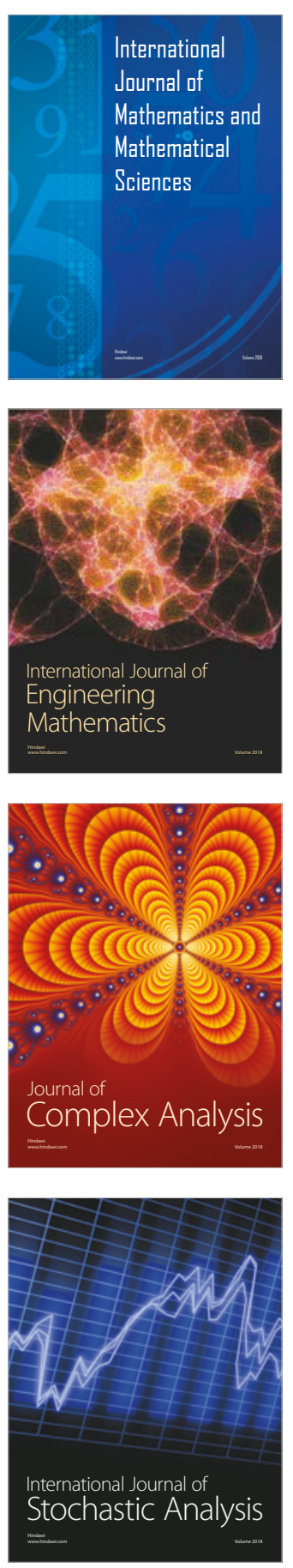
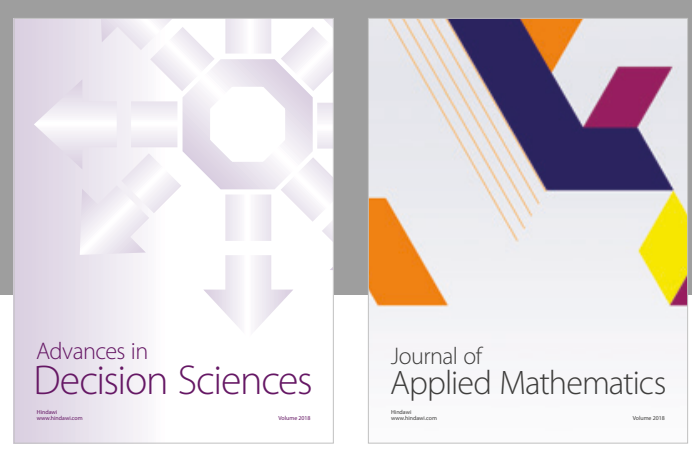

Journal of

Applied Mathematics
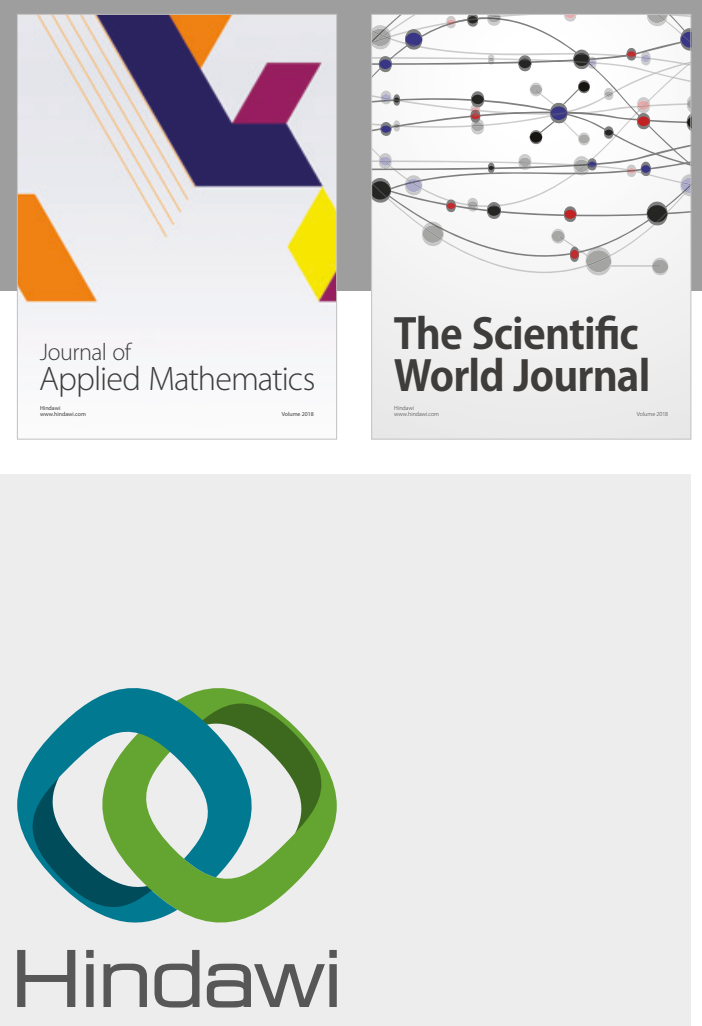

Submit your manuscripts at

www.hindawi.com

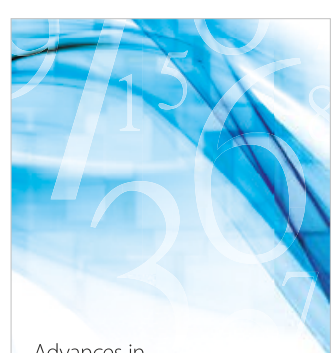

Advances in
Numerical Analysis
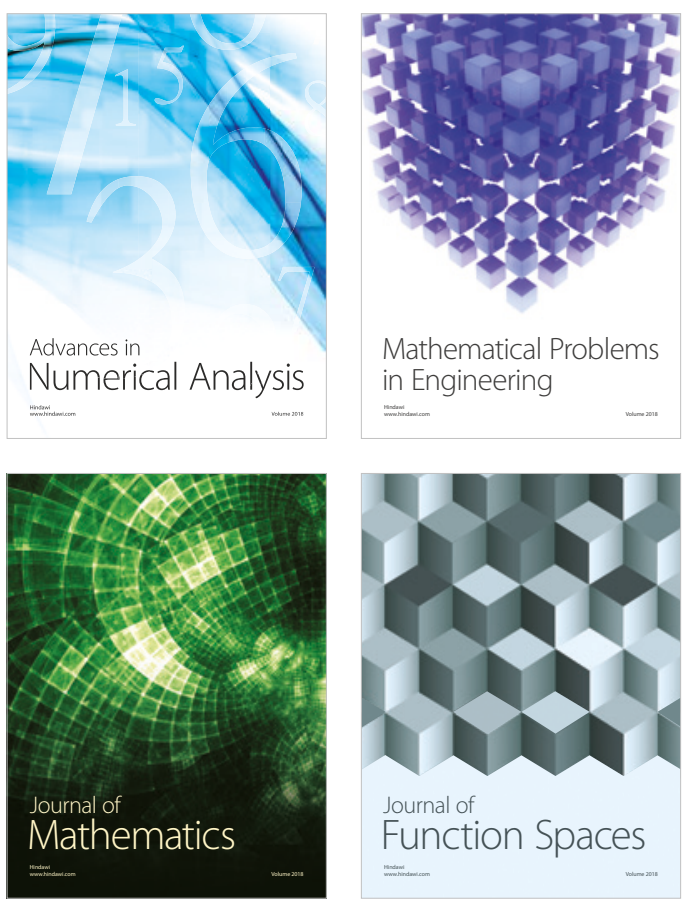

Mathematical Problems in Engineering

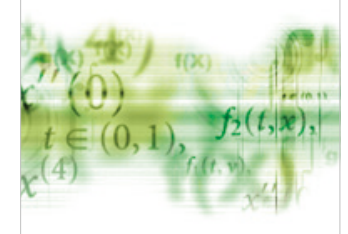

International Journal of

Differential Equations

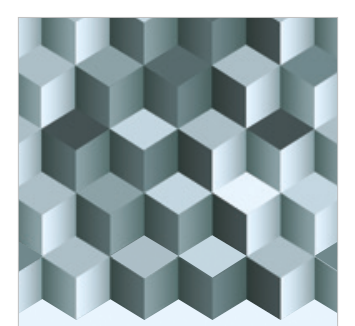

Journal of

Function Spaces

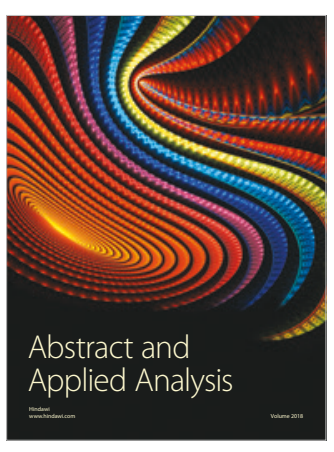

The Scientific

World Journal

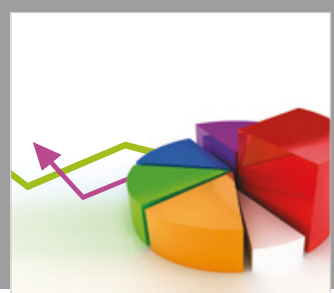

Journal of

Probability and Statistics
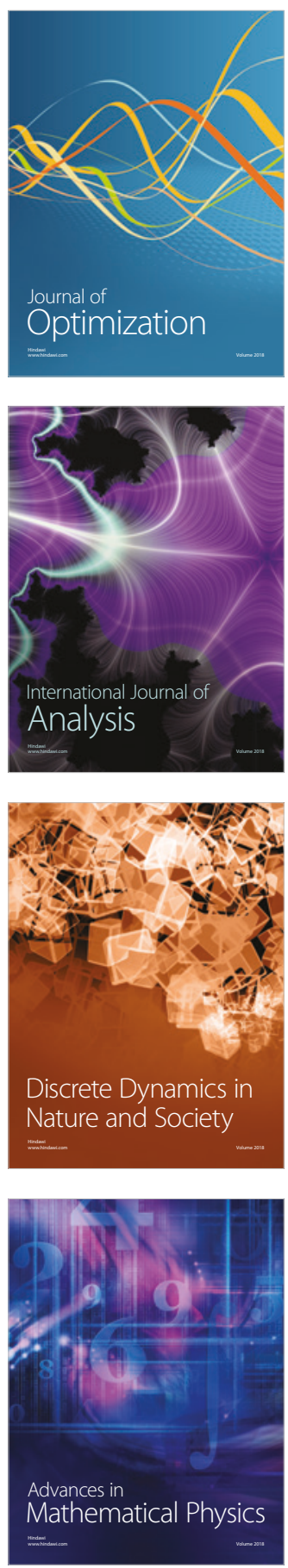